\title{
AN INVESTIGATION OF THE PSYCHOLOGICAL \\ FACTORS DETERMINING THE MAGNITUDE \\ OF AUDITORY SENSATION
}

\author{
L.C. DE JAGER
}

UNIVERSITY OF STELLENBOSCH

OPSOMMING

\begin{abstract}
Twintig toetslinge, 17 mans en 3 dames, tussen die ouderdomme 18 en 26 jaar is onder verskillende eksperimentele situasies getoets om die invloed van 'n aantal sielkundige faktore op die bepaling van luidheid te bepaal. Die metode van konstante stimuli is gebruik om die luidheidspeil onder die verskillende eksperimentele situasies te verkry. Die resultate van die ondersoek word bespreek in terme van toekomstige navorsing op hierdie gebied asook die implikasies wat dit vir die bedryf inhou.
\end{abstract}

The fact that noise is becoming an ever increasing problem can be explained and sustained by the following examples: R70 million was recently claimed from airport officials by schools in the vicinity of Los Angeles to finance noise damping projects. The British Government yearly spends about R1 million on research specifically directed at the reduction of aircraft noise (Van Niekerk, 1970). Haak (1970) states that South Africa's increase in industrial production amounts to about 8 per cent per annum, which means that industrial noise disturbance will also be more or less doubled in 10 years' time. In addition, if we consider the fact that the average sales of new motor vehicles increase by an average of 10 per cent per annum, which represents a noise increase of one decibel each year, it is equivalent to an increase of 10 decibels within 10 years' time and therefore a substantial increase in the noise problem.

In view of this and related problems, researchers have for some time tried to measure the magnitude of the annoyance caused by noise. The objective assessment of the magnitude of auditory sensation (pure loudness) serves as a basis for determining techniques to measure annoyance caused by noise more accurately. Having such an index of annoyance any unwanted sound from the environment in which man exists can therefore be assessed and minimised or even eliminated. 
Consequently it will also be easier to control and eliminate noise which affects performance or production of employees and which may cause hearing disorders among workers.

The determination of the magnitude of auditory sensation is not an easy task since it can be influenced by a number of environmental (external) and psychological (internal) factors.

The purpose of this study, therefore, was to investigate some of the psychological factors that may influence the determination of the magnitude of auditory sensation.

\section{THE DETERMINATION OF THE MAGNITUDE OF AUDITORY SENSATION ("PURE LOUDNESS")}

Considering psychological principles involved in determining "pure loudness" (magnitude of auditory sensation) a firm definition is required. For the purpose of this study it can be defined as "the ability of the normal human being to perceive and discriminate between sounds of different magnitude" (ISO, 1972, p.2).

It is reasoned that if the loudness function be ascertained by asking individuals to perceive and discriminate between sounds of different intensity, care should be taken to construct an experiment that would lead to optimum accuracy and objectivity. The results of research so far in this field have a shortcoming to the extent that the exact experimental procedures are not always reported satisfactorily and that biasing factors are not always considered.

In view of the above shortcomings the following factors and their influences were investigated.

\section{Motivational level of subjects}

The motivational level of subjects in this kind of research cannot easily be assessed, and therefore some investigators had to rely on their experimental instructions to ensure uniformity in this regard (Bugelski, 1951; Gault and Goodfellow, 1940; Goodfellow, 1946). In order to have some control over motivation, subjects should either be motivated positively or negatively in different experimental sessions. Positive motivation can be achieved through encouragement, prizes, praise, knowledge of results, and monetary rewards (Anastasi, 1967). Negative motivation can be generated by threat, punishment, reproof, discouragement, and criticism (Anastasi, 1967; Woodworth \& Schlossberg, 1960). 
Zwislocki, Maire, Feldman and Rubin (1958) found a shift in the threshold of audibility for a $1000 \mathrm{~Hz}$ tone when monetary rewards and feedback were used to motivate test subjects.

It was also noted that subjects with an initial low threshold showed a greater improvement in threshold than subjects with a relatively high initial threshold. A significant improvement in threshold was noted by Lucaszewski and Elliot (1962) when feedback and monetary rewards were used in combination. Swets and Sewall (1963) found no improvement in signal detection when the motivational level was increased.

\section{Feedback (knowledge of results)}

Feedback or knowledge of results can, for the purpose of this article, be defined as "giving the subject some information about his performance on successive trials" (Underwood, 1966, p.334). Feedback can be given in several ways, for example, by means of lights, buzzers, counters, or verbally. In this context feedback has several functions.

The following are three of the most important ones: (a) motivation, (b) reinforcement and (c) providing information (Lucaszewski \& Elliot, 1962; Underwood, 1966).

Several researchers reported on the effect of feedback on performance (Gundy, 1961; Lucaszewski \& Elliot, 1962). Sinaiko (1961) observed a significant increase in accuracy of signal detection when feedback was given. Similar results were obtained by Gundy (1961).

Investigating the effect of feedback on the auditory threshold, Lucaszewski and Elliot (1962), however, found a decrease in auditory threshold when feedback was used with a forced choice technique.

\section{The time-order-error}

When two stimuli are always presented in the same order for comparison purposes, the second stimulus is systematically overestimated or underestimated. This tendency to overestimate or underestimate the second stimulus gives rise to a negative time-order-error, whereas systematic underestimation gives rise to a positive time-order-error (Guilford, 1954; Postman, 1946).

An auditory time-order-error is usually involved when a psychophysical experiment, involving the discrimination between the loudness of a standard reference sound and the loudness of a variable sound, is conducted. When the time interval between the two stimuli is increased from 1 to 3 seconds, the time-order-error is positive. When the time interval is 
increased from 4 to 6 seconds, it becomes increasingly negative (Guilford, 1954; Postman, 1946; Woodworth \& Schlossberg, 1960).

Several writers like Postman (1949), Tresselt (1948), and Poulton and Stevens (1955) have reported on the time-ordererror in auditory perception. To eliminate the auditory timeerror Reichardt and Niese (1970) recommend equal durations of 500-1000 milliseconds for the reference stimulus, silent interval, and variable stimulus.

\section{The time of day when comparison judgements are made}

As a result of the lack of information regarding the above aspect, special attention was devoted to it as will be discussed presently. According to Reichardt and Niese (1970, p.1088) the judgement of subjects does not form an equation, but varies from moment to moment.

\section{The effect of practice on auditory thresholds}

Psychophysical experiments usually involve the repetition of certain tasks by the same subject. In some cases the repetition has a greater effect than in others, but it can be stated that successive trials generally result in a change of performance (Underwood, 1966). Practice can therefore be defined as sheer repetition (Anastasi, 1967, p.56).

Zwislocki, et.al. (1958) found that the practice effect decreased with an increase in frequency when the threshold of audibility was determined for $100 \mathrm{~Hz}$ and $1000 \mathrm{~Hz}$ tones. The improvement in the threshold of audibility was slightly smaller at $1000 \mathrm{~Hz}$ than at 100 Hz.

It is therefore apparent that practice influences the thresholds of audibility for $100 \mathrm{~Hz}$, $125 \mathrm{~Hz}, 125 \mathrm{~Hz}$, and $1000 \mathrm{~Hz}$ tones, but that the magnitude of this effect decreases with an increase in frequency (Swets \& Sewall, 1963; Zwislocki, et.al., 1958).

\section{HYPOTHESES}

To determine the influence and magnitude of the aforementioned factors on the determination of magnitude of auditory sensation, the following null hypotheses were tested:

1. Perceived loudness levels do not differ under conditions of positive and negative motivation. 2. The time of the day at which the judgements are made does not bring about different perceived loudness levels. 3. A change in the order of presentation of the reference signal and sound signal does not bring about different perceived loudness levels. 4 . The fixed 
vs. random order of presentation of sound tapes does not result in differently perceived loudness levels.

\section{METHOD}

\section{Equipment}

The following equipment and apparatus were used:

1. Test cubicle - Subjects were tested in an acoustic room fitted with loudspeaker, intercommunication unit, electric blower fan, electric light, a comfortable chair, carpet, and a microphone connected to a sound level meter. The latter was used to calibrate the equipment. See Figure 1 for further detail. 2. A good quality stereophonic tape recorder. 3. A good quality stereophonic amplifier. 4. A loudspeaker. 5. Calibrated dB attenuator. 6. Buffer amplifier/mixer. This piece of equipment was used for mixing the signals from the two tracks of the tape recorder and to match the input of the $\mathrm{dB}$ attenuator to the output of the tape recorder.

7. An impulse precision Sound Level Meter for calibration purposes. 8. A Maico Audiometer to conduct hearing tests.

The total equipment chain can be seen in Figure 1.

\section{Experimental design and procedure}

Twenty subjects, 17 male and 3 female, between 18 and 26 years of age with normal hearing abilities were used to determine the equal loudness levels for different sound signals by means of the method of constant stimuli. The loudness of a specific sound signal was determined by comparing the loudness of that sound signal with the loudness of a standard reference signal at a constant sound pressure level $(75 \mathrm{~dB}$ re $20 \mu \mathrm{Pa})$. The sound pressure level of a specific sound is measured in terms of the physical energy of that sound (in decibel) and corresponds with the loudness of that sound which is psychological and is perceived (Morgan \& King, 1971). Each sound signal was presented at a number of different sound pressure levels varying discretely from that sound pressure level which has the same loudness as the reference signal.

The discrete sound pressure levels (for a specific sound signal) and the constant reference signal were presented to the subject alternatively. These discrete levels were pre- 
sented three times. Subjects were requested to indicate verbally by means of the intercommunication unit which of the two signals were the louder. Every sound signal was presented at six different discrete levels. This resulted in eighteen comparisons for every sound signal. This procedure resulted in a balance between the loudness of the reference signal and the loudness of the sound signal, rather than actual loudness measurement.

During every experimental session three different sound signals were used, resulting in a total of 54 judgements.

From the subject's responses an equal loudness level for every sound signal was determined. This equal loudness level was assumed to be midway between the following two loudness levels: (a) that level at which the subject judged the sound signal to be louder than the reference signal and (b) that level at which he judged it to be softer than the reference signal.

The 20 subjects were tested under 4 different experimental conditions. All experimental sessions took place in the afternoon, except one session for each subject which took place in the evening to determine the effect of the time of day on loudness judgement.

To determine the effect of positive motivation the subjects were praised and given

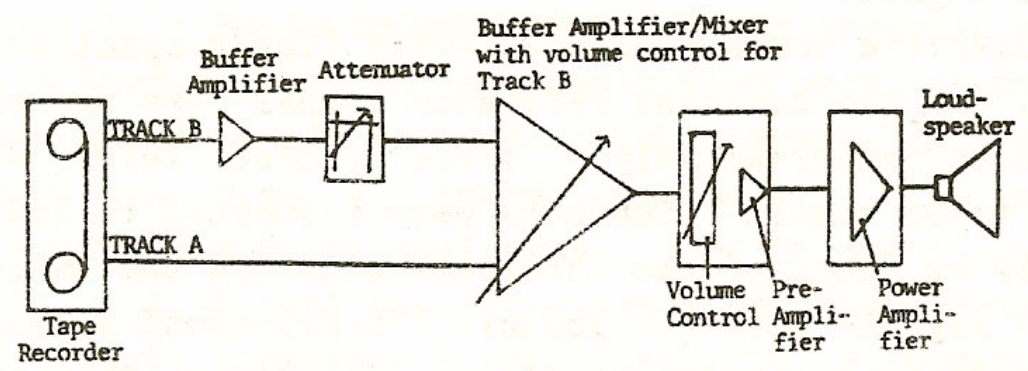

Figuur 1. Total equipment chain.

feedback on every judgement, (e.g. "You are doing very well", or "Your answer is correct"). No monetary rewards were given in this investigation. To induce negative motivation, the same sound signals were presented for loudness judgement, but no feedback was given and subjects were occasionally criticised on their performance, (e.g. "Your answers up to now are all wrong", or "Give your answers quicker!").

Tapes were presented in a fixed order to 10 subjects and in a random order to 10 other subjects to determine the effect of practice. 
To determine the effect of the time-order-error on loudness judgement all subjects were subjected to a tape consisting of the reference signal followed by the sound signal, and to another tape consisting of the sound signal followed by the sound signal, and to another tape consisting of the sound signal followed by the reference signal. Both tapes consisted of the same sound signals and reference signal.

Reference signals and sound signals were pre-recorded on good quality magnetic tapes. Altogether six tapes were prepared, one calibration tape and six experimental tapes. The calibration tape was used to calibrate the apparatus before every experimental session.

Each experimental tape was divided into two sections. The first section, called the preliminary experiment, was used to determine a setting on the attenuator which represented an approximate equal loudness attenuation for every subject. In this section the reference signal (recorded on one track) was presented first, followed by the first sound signal (recorded on the other track), repeated for 24 cycles: After a silent interval the reference signal was presented again, followed by the second sound signal, repeated for 24 cycles. This procedure was continued until all three sound signals were presented. The duration of the reference signal was one second.
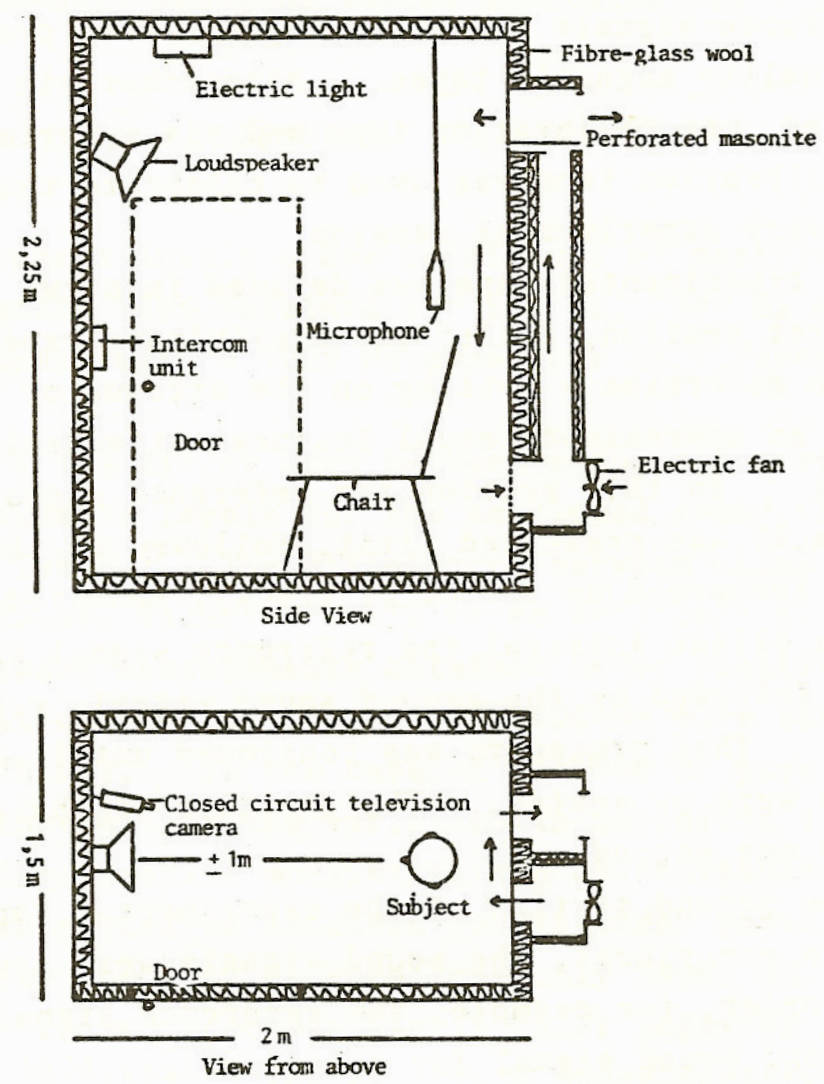
On the second section of the experimental tapes, called the main experiment, the sound signals were presented in a random order, for example, the reference signal followed by the second sound signal for seven cycles, then the reference signal followed by the first sound signal for seven cycles. The different random sequences for the different experimental tapes were compiled by Green (1972). The sequences were compiled in such a way as to allow every sound signal to be presented 18 times, three times at the same discrete level. For the three stimuli on every tape, 54 comparison judgements were thus required. On all tapes the reference signal was followed by the sound signal, except for one tape on which the order was reversed to determine the time-order-error. Experimental sessions lasted approximately 40 minutes each.

\section{RESULTS}

\section{Motivation}

Perceived loudness levels under conditions of positive and negative motivation were obtained for $500 \mathrm{~Hz}, 2000 \mathrm{~Hz}$ and $4000 \mathrm{~Hz}$ pure tones, with a $1000 \mathrm{~Hz}$ pure tone as reference signal.

An analysis of the differences between means and variances of perceived loudness levels for the mentioned sound signals can be seen in Table 1. The differences between means and variances are insignificant for all three frequencies. The correlation between measurements obtained under positive and negative motivation for the $500 \mathrm{~Hz}$ and $4000 \mathrm{~Hz}$ pure tones is significant $(\mathrm{p}<0,01)$. In the case of the $500 \mathrm{~Hz}$ pure tone, it is evident that $41 \%$ of the variation in perceived loudness levels under negative motivation can be attributed to the variation in perceived loudness levels under positive motivation. For the $4000 \mathrm{~Hz}$ pure tone only $38,9 \%$ of the variation in perceived loudness levels under negative motivation can be predicted by the variation under positive motivation. On the basis of the above findings the hypothesis, that perceived loudness levels do not differ under different motivational conditions, can therefore not be rejected. 
TABLE 1

Means, Variances and Correlations of Perceived Loudness Levels (in $\mathrm{dB}$ re $20 \mu \mathrm{Pa}$ ) for Three Different Sound Signals

Obtained under Positive and Negative Motivation

\begin{tabular}{|c|c|c|c|c|c|c|c|c|c|}
\hline $\begin{array}{l}\text { Sound } \\
\text { Signal }\end{array}$ & $\begin{array}{l}\bar{X} \\
\text { P.M. }\end{array}$ & $\begin{array}{c}\bar{Y} \\
\text { N.M. }\end{array}$ & $\bar{X}-\bar{Y}$ & $\begin{array}{l}t \text { of } \\
\bar{X}-\bar{Y}\end{array}$ & $\begin{array}{l}s^{2} x \\
\text { P.M. }\end{array}$ & $\begin{array}{l}S^{2} y \\
\text { N.M. }\end{array}$ & $s^{2} x-s^{2} y$ & $\begin{array}{c}c \text { of } \\
s^{2} x-s^{2} y\end{array}$ & $r_{x y}$ \\
\hline 1. $500 \mathrm{~Hz}$ & 67,85 & 67,70 & 0,15 & 0,232 & 13,328 & 10,01 & 3,318 & 0,793 & $0,64^{* A}$ \\
\hline 2. $2000 \mathrm{~Hz}$ & 74,05 & 74,25 & $-0,20$ & 0,163 & 19,548 & 22,188 & $-2,640$ & 0,284 & 0,321 \\
\hline 3. $4000 \mathrm{~Hz}$ & 67,85 & 67,90 & $-0,05$ & 0,058 & 19,428 & 18,490 & 0,938 & 0,134 & $0,62^{\circ \mathrm{s}}$ \\
\hline
\end{tabular}

" $p=0,01$

P.M. = Positive Motivation

N.M. = Negative Motivation and Stress

TABLE 2

Means, Variances and Correlations of Perceived Loudness

Levels (in $\mathrm{AB}$ re $20 \mu \mathrm{Pa}$ ) for Three Different Sound Signals Obtained during the Afternoon and the Evening

\begin{tabular}{|c|c|c|c|c|c|c|c|c|c|}
\hline $\begin{array}{l}\text { Sound } \\
\text { SignaI }\end{array}$ & $\begin{array}{c}\mathrm{X} \\
\text { Day }\end{array}$ & $\begin{array}{c}7 \\
\text { Evening }\end{array}$ & $\bar{X}-\bar{Y}$ & $\begin{array}{l}t \text { of } \\
X-Y\end{array}$ & $\begin{array}{l}s^{2} x \\
\text { Day }\end{array}$ & $\begin{array}{c}s^{2} y \\
\text { Evening }\end{array}$ & $s^{2} x-s^{2} y$ & $\begin{array}{r}t \text { of } \\
s^{2} x-s^{2} y\end{array}$ & ${ }^{5} x y$ \\
\hline $\begin{array}{c}\text { 1. } 500 \mathrm{~Hz} \\
\text { tone }\end{array}$ & 67,85 & 67,45 & 0,40 & 0,623 & 13,328 & 12,848 & 0,480 & 0,109 & $0,70^{* * 4}$ \\
\hline 2. $2000 \mathrm{~Hz}$ & 74,05 & 73,40 & 0,65 & 0,608 & 19,548 & 10,24 & 9,308 & 1,452 & 0,276 \\
\hline $\begin{array}{l}\text { 3. } 4000 \mathrm{~Hz} \\
\text { tone }\end{array}$ & 67,85 & 67,90 & $-0,05$ & 0,052 & 19,428 & 15,99 & 3,438 & 0,484 & $0,515^{\circ}$ \\
\hline
\end{tabular}

- $p<0,05$

000,001

\section{The time-order-error}

Results obtained for Tape No. 4 (reference signal followed by sound signal) and Tape No.5 (sound signal followed by reference signal) can be seen in Table 3. Both tapes consisted of the same sound signals $(500 \mathrm{~Hz}, 1000 \mathrm{~Hz}$ and $4000 \mathrm{~Hz}$ pure tones) and reference signal (1000 $\mathrm{Hz}$ pure tone).

$500 \mathrm{~Hz}$ pure tone. The differences between means and variances of perceived loudness levels obtained for the two conditions are insignificant (Table 3). The significant positive 
correlation $(p<0,001)$ between the two sets of measurements enables us to predict $61,3 \%$ of the variation in loudness levels for Tape 5 by the variation in the loudness levels for Tape 4 .

TABLE 3

Means, Variances and Correlations of Perceived

Loudness Levels (in $\mathrm{dB}$ re $20 \mu \mathrm{Pa}$ ) for Three

Different Sound Signals Obtained for Tape No. 4

and Tape No. 5 (Reversed Order)

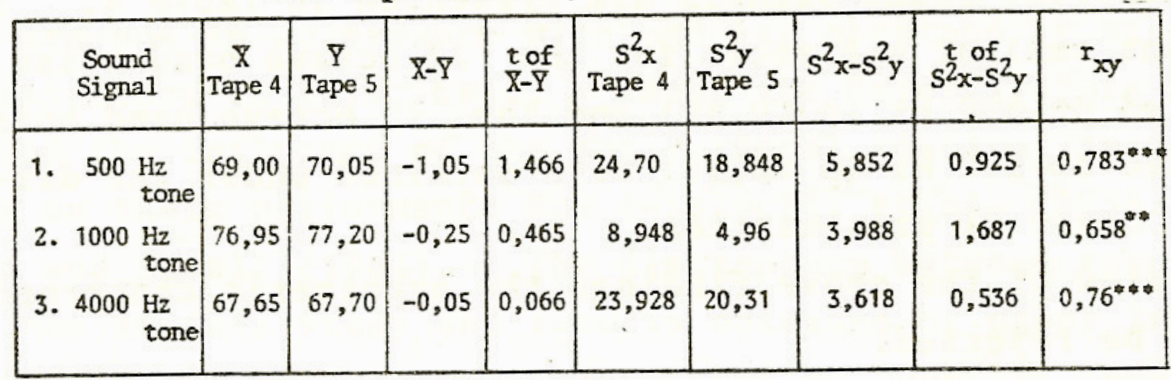

* $p<0,01$

000,001

Tape no. 4: Reference signal followed by sound signal.

Tape no. 5: Sound signal followed by reference signal.

$1000 \mathrm{~Hz}$ tone pure tone and $4000 \mathrm{~Hz}$ pure tone. Insignificant differences between the means and variances of perceived loudness levels for both the $1000 \mathrm{~Hz}$ and $4000 \mathrm{~Hz}$ pure tones were found. The positive correlation between the measurement for Tape 4 and for Tape 5 is significant $(\mathrm{p}<0,01)$. A stronger and more significant relationship $(\mathrm{p}<0,001)$ was found for the $4000 \mathrm{~Hz}$ pure tone. These relationships indicate a relatively high degree of consistency for perceived loudness levels between the two different conditions for both frequencies. The null hypothesis, which states that a change in the order of presentation of the reference signal and sound signal does not bring about different perceived loudness levels, cannot be rejected

\section{The practice effect}

To determine the practice effect experimental tapes (conditions) were administered in a fixed order to ten subjects and in a random order to ten other subjects.

The means and variances of loudness levels obtained for the different sound signals are presented in Table 4. Significant smaller variances for the 1/3 octave band noise centered on $500 \mathrm{~Hz}(\mathrm{p}<0,10)$ and the $1 / 3$ octave band noise centered on $250 \mathrm{~Hz}(\mathrm{p}<0,10)$ were obtained under the different order of presentation.

In view of the above findings the hypothesis concerned cannot be rejected. 
In view of the above findings, conclusions can be drawn with respect to future research in this field as well as the possible implications of the results for industry.

TABLE 4

Means and Variances of Perceived Loudness

Levels (in $\mathrm{dB}$ re $20 \mu \mathrm{Pa}$ ) Obtained for Dif-

ferent Tapes presented in Fixed and Random

Order for Two Independent Groups

\begin{tabular}{|c|c|c|c|c|c|c|c|c|c|}
\hline \multirow[b]{2}{*}{$\begin{array}{l}\text { Tape } \\
\text { No. }\end{array}$} & \multirow[b]{2}{*}{$\begin{array}{l}\text { Sound } \\
\text { Signal }\end{array}$} & \multicolumn{2}{|c|}{$\begin{array}{l}\text { Fixed Order } \\
(X)\end{array}$} & \multicolumn{2}{|c|}{$\begin{array}{c}\text { Random Order } \\
(Y)\end{array}$} & \multirow[b]{2}{*}{$X-Y$} & \multirow[b]{2}{*}{$\stackrel{t}{t}$ of } & \multirow[b]{2}{*}{$s^{2} x-s^{2} y$} & \multirow[b]{2}{*}{$\underset{S^{2} x-S^{2} y}{F}$} \\
\hline & & $\mathrm{X}$ & $s^{2} y$ & $Y$ & $s^{2} y$ & & & & \\
\hline 3 & $\begin{array}{l}500 \mathrm{~Hz} \\
1 / 3 \text { oct. } \\
\text { noise }\end{array}$ & 68,20 & 20,96 & 68,60 & 6,04 & $-0,40$ & 0,231 & 14,92 & $3,47^{*}$ \\
\hline 6 & $\begin{array}{l}250 \mathrm{~Hz} \\
1 / 3 \text { oct. } \\
\text { noise }\end{array}$ & 70,70 & 28,61 & 71,20 & 6,96 & $-0,50$ & 0,252 & 21,65 & $4,111^{\circ}$ \\
\hline
\end{tabular}

The results obtained under positive and negative motivation are not in accordance with results obtained by other investigators in this field. Among the investigators who studied the influence of the motivational level of test subjects on their performance are Zwislocki, et.al. (1958) and Swets and Sewall (1963). The discrepancy between results obtained in this study and results obtained by other investigators could be due to the fact that no monetary rewards were used in this study. Instead of monetary rewards, feedback on the correctness of their responses and praise were used as incentives. When these motivational factors (feed-back and praise) were replaced by criticism and no-feedback, no significant differences in perceived loudness levels were noted.

Results obtained during different times of experimentation reveal no significant differences in perceived loudness levels for the frequencies studied.

Considering the results obtained whilst studying the time- order-error, it is evident that the results obtained in this study do not indicate significant time-errors. Postman (1964) found significant time-errors when the loudness of pure tones were determined. The absence of a 
significant time-error in this study may be the result of the method of constant stimuli which was employed. Stevens (1955) noted that the magnitude of the time-order-error was not very large when the method of constant stimuli was used.

Results obtained whilst studying the practice effect indicate insignificant differences between means, but significant differences between variances for $250 \mathrm{~Hz}$ and $500 \mathrm{~Hz} 1 / 3$ octave band noise. The differences between the variance for these two frequencies are only significant at the 0,10 level. Rather similar results were obtained by Swets and Sewall (1963), and Zwislocki, et.al. (1958). They reported a decrease in the practice effect with an increase in frequency, the practice effect being limited to the lower frequencies.

Conclusively it can be mentioned that various countries developed their own measuring techniques regarding noise measurement in the past. These techniques were based on research undertaken within the different countries. Depending on which measuring techniques were used almost every country established its own noise standards.

The implications of these differing standards are therefore clear. If, for instance, the standards of France and South Africa differ, noise of aircraft imported from France may not conform to South African standards. The same argument can be used regarding goods exported from South Africa to other countries.

The problem regarding differing measuring techniques and consequently differing standards lead to the design of an international "Round Robin" experiment in which the results of this present study were incorporated.

The purpose of the international investigation is to compare existing methods of noise measurement and to select that method which gives the best results. Once the "best" method has been selected, noise can be measured uniformly on an international basis.

\section{SUMMARY}

This research deals with some psychological factors that may influence the determination of the magnitude of auditory sensation or pure loudness. Several factors and their influences are discussed. 17 Male and 3 female subjects between 18 and 26 years of age were tested under several different experimental conditions using the method of constant stimuli. Results are discussed in terms of both future research and implications for industry. 


\section{REFERENCES}

Anastasi, Anne. Psychological Testing. New York: McMillan, 1967.

Bugelski, B.R. A First Course in Experimental Psychology. New, York: Holt, 1951.

Gault, L.H. \& Goodfellow, L.D. Sources of error in psychophysical measurements. Journal of General Psychology, 1940, 23, 197-200.

Goodfellow, L.D. Significant incidental factors in the measurement of auditory sensitivity. Journal of General Psychology, 1964, 35, 37-41.

Green, W.B. A study of impulsive acoustics. Master's Thesis. Durban: University of Natal, 1972.

Guilford, J.P. Psychometric Methods. New York: McGraw-Hill, 1954.

Gundy, R.F. Auditory detection of an unspecified signal. Journal of the Acoustical Society of America, 1961, 33(8), 1008-1012.

Haak, J. F. W. Opening address at the Conference on Noise. Cape Town, February, 1970.

ISO/TC43/SC1/SGA (South Africa) ${ }^{2}$ - Outlines of the proposed international investigation concerning the determination of magnitude of auditory sensation, 1972.

Lucaszewski, J.S. \& Elliot, D.N. Auditory threshold as a function of forced choice technique, feedback and levels of motivation. Journal of the Acoustical Society of America, 1962, 34(2), 223-228.

Morgan, C.T. \& King, R.A. Introduction to Psychology. New York: McGraw-Hill, 1971.

Postman, L. The time-error in auditory perception. American Journal of Psychology, 1946, 59(3), 193-219.

Postman, L. \& Egan, J.P. Experimental Psychology: An Introduction. New York: Harper, 1949.

Poulton, E.C. \& Stevens, S.S. On the halving and doubling of white noise. Journal of the Acoustical Society of America, 1955, 27(2), 329-331.

Reichardt, W. \& Niese, H. Choice of sound duration and silent intervals for tests and comparison signals in the subjective measurement of loudness level. Journal of the Acoustical Society of America, 1970, 47(4), (Part 2).

Sinaiko, W. H. Selected Papers on Human Factors in the Design and Use of Control Systems. New York: Dover Publications, 1961.

Stevens, S.S. The measurement of loudness. Journal of the Acoustical Society of America, $1955,27(5), 815-829$.

Swets, J.A. \& Sewall, S.T. Invariance of signal detectability over stages of practice and levels of motivation. Journal of Experimental Psychology, 1948, 61, 335-342.

Tresselt, M.E. Time-error in successive comparison of tonal pitch. American Journal of Psychology, 1948, 61(3), 335-342.

Underwood, B.J. Experimental Psychology. New York: Holt, 1960.

Van Niekerk, C.G. Vliegtuiggeraas. Paper presented at the conference on noise. Cape Town, February, 1970.

Zwislocki, J., Maire, F., Feldman, A.S. \& Rubin, H. On the effect of practice and motivation on the threshold of audibility. Journal of the Acoustical Society of America, 1958, 30(4), 254-262. 